ISSN: 0213-2060

DOI: https://doi.org/10.14201/shhme20213916994

\title{
PETRIFICANDO LA RIQUEZA FAMILIAR MÁS ALLÁ \\ DE LA FRONTERA. LA CONSTRUCCIÓN COMO ELEMENTO \\ DE CREACIÓN DE IDENTIDAD Y MEMORIA NOBILIARIA ENTRE LEÓN Y PORTUGAL ${ }^{1}$
}

\section{Petrifying the Family Wealth beyond the Border The Construction as an Element for Creating Identity and Nobiliary Memory between León and Portugal}

\author{
Inés CALDERÓN MEDINA \\ Departamento de Ciencias Históricas y Teoría de las Artes. Universidad de las Islas Baleares. Edificio Ramon LLull, \\ Carretera de Valldemosa, km. 7.5. 07122. Palma. España. C.e: inescalderon1@hotmail.com. ORCID: https:// \\ orcid.org/0000-0002-1274-3691
}

Recibido: 2021-02-11

Revisado: 2021-02-16

Aceptado: 2021-03-23

RESUMEN: A lo largo de los siglos XI y XIII, la nobleza invirtió gran parte de su patrimonio en la construcción de edificios, civiles y eclesiásticos, para crear su identidad y memoria. A través del análisis de los restos arquitectónicos, la documentación diplomática, las Inquiriçōes Gerais de 1258 y las obras genealógicas portuguesas se estudiará cómo la nobleza asentada en el territorio transfronterizo entre Bragança, Chaves y Zamora, Toro, Sanabria y Cabrera financió la construcción de casas, castillos, iglesias y monasterios para crear su identidad, memoria e imagen de su poder.

Palabras clave: Petrificación de la riqueza; nobleza transfronteriza; Bragança; Ponce de Cabrera; Cabrera y Ribera.

ABSTRACT: Throughout the 11th and 13th centuries, the nobility invested significant part of their heritage in the construction of buildings, civil and ecclesiastical, to create their identity and memory. Through the analysis of the architectural remains, the diplomatic documentation, The General Inquiriçôes from 1258 and the Portuguese genealogical works,

1 Esta investigación se ha desarrollado dentro del proyecto «Petrifying Weatlh. The Southern European Shift to Masonry as Collective Investment in Identity, c. 1050-1300» del CCHS-CSIC, Instituto de Historia, financiado por el programa de investigación e innovación Horizonte 2020 de la Unión Europea bajo el acuerdo n. ${ }^{\circ} 695515$. 
PETRIFICANDO LA RIQUEZA FAMILIAR MÁS ALLÁ DE LA FRONTERA. LA CONSTRUCCIÓN COMO ELEMENTO DE CREACIÓN DE IDENTIDAD Y MEMORIA NOBILIARIA ENTRE LEÓN Y PORTUGAL INÉS CALDERÓN MEDINA

it will be analysed how the nobility settled in the cross-border territory between Bragança, Chaves and Zamora, Toro, Sanabria and Cabrera financed the construction of houses, castles, churches and monasteries in order to create their identity, memory and image of their power.

Keywords: Petrification of wealth; cross-border nobility; Bragança; Ponce de Cabrera; Cabrera y Ribera.

SUMARIO: 0 Introducción. 1 La nobleza y la construcción en el espacio transfronterizo. 1.1. La promoción de monasterios como lugares de identidad y memoria familiar. 2 Los Bragança, Castro de Aveláes y Moreruela. Monasterios e identidad nobiliaria en las obras genealógicas portuguesas. 3 Casas, castillos e identidad nobiliaria. El testimonio de las Inquiriçôes Gerais de 1258. 4 Conclusiones. 5 Referencias bibliográficas.

\section{INTRODUCCIÓN}

En 1096 Alfonso VI trazaba una frontera que dibujaba un nuevo condado portucalense, que entregó a su hija Teresa y a su esposo el conde Enrique. Esta línea divisoria no impidió la permanencia de los vínculos culturales, feudovasalláticos y parentelares que unían a la nobleza asentada en este amplio espacio ahora dividido; que, sin embargo, tuvo que adaptarse a la situación tras el nacimiento de una nueva entidad política. Estas circunstancias facilitaron una gran movilidad entre los reinos, de los nobles que poseían bienes e intereses familiares a ambos lados de la nueva frontera. En los últimos años se han realizado diversos estudios sobre la nobleza transfronteriza y su movilidad entre los reinos a lo largo de los siglos XI-XIII. Se han analizado las causas, los ciclos y las consecuencias de su movilidad, que fue utilizada por los propios nobles para destacarla como una característica identitaria ${ }^{2}$. Los miembros de las parentelas, que extendieron su poder y patrimonio por varios reinos ibéricos, utilizaron para construir su identidad, mecanismos como la antroponimia y la heráldica, pero también la promoción de construcciones, laicas y eclesiásticas, que eran el símbolo de su poder, y a las que vinculaban su imagen y memoria ${ }^{3}$.

A lo largo de varias generaciones, los miembros de la parentela fueron conscientes de la relación que sus antepasados habían mantenido con ciertos castillos, iglesias y monasterios que habían patrocinado, pues ellos aún mantenían derechos de patronazgo, que generaron una importante fuente de ingresos a lo largo de los siglos. Así lo demuestran las listas de patronos conservadas en el monasterio de Ferreira de Pallares o las del

2 Calderón Medina, Inés y Ferreira Martins, João Paulo. «Beyond the border. The aristocratic mobility between the kingdoms of Portugal and León (1157-1230)», E-journal of Portughese History, 2014 , vol. 12, n. ${ }^{\circ}$ 1, pp. 1-48. Calderón Medina, Inés. «La movilidad nobiliaria en las fuentes medievales hispánicas. Hagiografías, cantigas y genealogías». En Reglero de la Fuente, Carlos (ed.). Poderes, espacios y escrituras. Los reinos de Castilla y León (siglos XII-XIV). Madrid: Sílex, 2018, pp. 15-53.

3 Calderón Medina, Inés. Los Soverosa una parentela nobiliaria entre tres reinos. Poder y parentesco en la Edad Media Hispana, (ss. XI-XIII). Valladolid: Universidad de Valladolid, 2018, pp. 209-227. 
PETRIFICANDO LA RIQUEZA FAMILIAR MÁS ALLÁ DE LA FRONTERA. LA CONSTRUCCIÓN COMO

monasterio de Grijó, o las declaraciones de transmisión de los derechos de patronazgo que manifiestan los testigos de las Inquiriçóes. Todas ellas permiten observar cómo se mantenía en la memoria la pertenencia a un grupo de parentesco y a la importante fuente de ingresos que suponía su vinculación con una determinada iglesia o centro monástico ${ }^{4}$.

Este estudio se centrará en analizar la promoción de la construcción de determinados edificios, civiles o eclesiásticos, como un elemento de identidad de las familias asentadas en el amplio espacio comprendido entre el sur de Galicia, la tierra de Chaves y Tras-òs-Montes, y las tierras de Sanabria, la Cabrera, Valdeorras y el Campo de Toro, principalmente 5 . En este amplio espacio, en el que se está trazando una difusa, porosa y móvil frontera desde 1096 hasta 1297, se asientan grandes parentelas como los Bragança, Cabrera y Ribera, o los Cabrera, a quienes los monarcas intentan atraer a su servicio para mantener la tierra que dominan entre los límites de su reino. Estas grandes familias emparentarán entre sí en sucesivas ocasiones, y con ambas monarquías a lo largo de los siglos XI al XIII. Pero además de las parentelas magnaticias, en este espacio se asientan otras familias de una nobleza media con las que tienen vínculos de vasallaje.

En este espacio transfronterizo se aprecia una enorme movilidad de los miembros de estas familias. Promocionaron construcciones que representaban lugares de identidad, creando una red de espacios simbólicos que se extendían por encima de las fronteras de los reinos; constituyendo así, el propio espacio de poder de la parentela.

A pesar que desde el siglo XI se vive un proceso de petrificación de estructuras, es pequeño el porcentaje de las construcciones que ha llegado a nuestros días, aunque sí dejaron su huella en la documentación. A partir del análisis de las fuentes diplomáticas, principalmente monásticas, analizaremos las donaciones de los nobles que destinan una parte importante de su patrimonio para la construcción de los edificios. Asimismo, se empleará la Quarta alçada de las Inquiriçóes Gerais de 1258. A pesar de que se trata de una fuente regia de carácter fiscal, aporta numerosos datos acerca de la participación de los nobles en la construcción de ciertos edificios, y de su desuso o abandono ${ }^{6}$. Además, los testimonios orales en los que sus vasallos recuerdan y transiten, generación tras generación, la vinculación de los nobles con los edificios que construyeron o heredaron, permiten observar que fueron un elemento para crear la identidad y la imagen del poder de la nobleza. Asimismo, se utilizarán las fuentes genealógicas portuguesas en las que algunas familias introdujeron narrativas vinculándose a ciertos edificios que habían patrocinado, para crear su identidad ${ }^{7}$. Con esta combinación de fuentes, sumada a los restos materiales conservados, se pretende obtener una visión poliédrica acerca de cómo

\footnotetext{
4 Sottomayor Pizarro, José Augusto. Os patronos do mosteiro de Grijó: evolução e estrutura da familia nobre, séculos XI a XIV. Porto: Ediçóes Carvalhos de Bastos, 1995.

5 Véase Martín Viso, Iñaki. «La formación de la frontera con Portugal y su impacto en el occidente zamorano (siglos XII-XIII)», Studia Zamorensia, Segunda etapa, 2002, vol. VI, pp. 49-74.

6 Portugaliae Monumenta Historica, (ed.) Inquisitiones, vol I, Part II, Fas. VIII. Lisboa: Academia das Ciências de Lisboa, 1961. En adelante, PMH, INQ. 1258.

7 Se empleará el siguiente sistema de abreviaturas para referirse a los distintos livros de linhagens: LV (Livro Velho de Linhagens), LD (Livro de Linhagens do Deão) - Piel, Joseph y Mattoso, José. (eds). Livros Velhos de Linhagens. En Portugaliae Monumenta Historica. Nova Série, vol. I. Lisboa: Academia das Ciências de Lisboa, 1980 - y LL (Livro de Linhagens do Conde D. Pedro) - Mattoso, José. (ed.). Livro de Linhagens do
} 
PETRIFICANDO LA RIQUEZA FAMILIAR MÁS ALLÁ DE LA FRONTERA. LA CONSTRUCCIÓN COMO ELEMENTO DE CREACIÓN DE IDENTIDAD Y MEMORIA NOBILIARIA ENTRE LEÓN Y PORTUGAL INÉS CALDERÓN MEDINA

la identidad de la nobleza se articuló también a través de la promoción de la construcción de ciertos edificios laicos y eclesiásticos.

\section{LA NOBLEZA Y LA CONSTRUCCIÓN EN EL ESPACIO TRANSFRONTERIZO}

En el amplio espacio definido se asientan los Bragança, la segunda de las principales y más antiguas familias portuguesas ${ }^{8}$; los Cabrera, descendientes del magnate catalán Ponce de Cabrera; y los Cabrera y Ribera, que descienden de Fernando Fernandes de Toro, un Bragança casado con Elvira Alfonso, hija ilegítima de Alfonso VI de León. Se trata de familias magnaticias que emparentaron en numerosas ocasiones entre los siglos XI y XIII, generando una tupida red de parentesco e intereses, al tiempo que establecieron sucesivos enlaces, por vía legítima e ilegítima, con las monarquías leonesa y lusitana.

Pero además de estas grandes familias, la documentación permite identificar y reconstruir su red de clientes y vasallos. Una nobleza media, como los Sanabria, los descendientes de Pedro Menéndez Tyo, o de Mendo Bonfim, además de otros milites de menor implantación territorial. Ellos también participaron, de manera directa o indirecta, en la promoción de la construcción de distintos edificios, principalmente eclesiásticos?

\subsection{La promoción de monasterios como lugares de identidad y memoria familiar}

Los nobles destinaron una parte sustancial de su patrimonio a la construcción de los grandes edificios, principalmente monásticos. Entre los siglos XI y XIII se asiste a un proceso en el que la nobleza construye y mantiene sus monasterios particulares a los que se vincularon durante generaciones, convirtiéndolos en un lugar de creación de identidad y memoria del grupo de parentesco. Los monasterios, además de cumplir con las necesidades espirituales de la parentela, eran los lugares en los que se resolvían algunos conflictos entre los parientes, el refugio en los momentos de enfermedad o de viudedad, y espacios de sepultura y creación de memoria de los miembros de la parentela fundadora ${ }^{10}$.

Conde D. Pedro. En Portugaliae Monumenta Historica. Nova Série, vol. II. Lisboa: Academia das Ciências de Lisboa, 1980.

8 Sobre los Bragança véase. Sottomayor Pizarro, José Augusto. As linhagens medievais portuguesas. Estratégias. Oporto: Centro de Estudos de Genealogia, Heráldica e História da Família, Universidade Moderna, 1999, vol. I, pp. 225-238. Soares Machado, José Carlos. Os Bragançãos: história genealógica de uma linhagem medieval (séculos XI-XIII). Lisboa: Associação portuguesa de Genealogía, 2004. Ferreira do Amaral, José Augusto. «A linhagem dos Bragançãos- Parte I». Armas e Troféus, 2016, vol. 9, pp. 259-319 y "A linhagem dos Bragançãos- Parte II». Armas e Troféus, 2017, vol. 10, pp. 247-274.

9 Véase, Beceiro Pita, Isabel. «Los poderes seńoriales en los territorios fronterizos al Norte del Duero, ss. XIII-inicios del XIV)». Revista de Faculdade de Letras, 1998, vol. 15, n. ${ }^{\circ}$ 2, pp. 1085-1100.

10 Martínez Sopena, Pascual. «Aristocracia, monacato y reformas en el siglo XI y XII». En El monacato en los reinos de León y Castilla (siglos VII-XIII). Ávila: Fundación Sánchez-Albornoz, 2005, pp. 67-100. Martínez Sopena, Pascual. «Monasterios particulares, nobleza y reforma eclesiástica en León entre los siglos XI y XII». En VV. AA. Estudios de Historia medieval. Homenaje a Luis Suárez Fernández. Valladolid: Universidad de Valladolid, 1991, pp. 323-331. Pérez, Mariel. «El control de lo sagrado como instrumento de poder: los 
PETRIFICANDO LA RIQUEZA FAMILIAR MÁS ALLÁ DE LA FRONTERA. LA CONSTRUCCIÓN COMO ELEMENTO DE CREACIÓN DE IDENTIDAD Y MEMORIA NOBILIARIA ENTRE LEÓN Y PORTUGAL INÉS CALDERÓN MEDINA

A lo largo del siglo XII, la mayor parte de los propietarios de monasterios particulares fueron entregando sus porciones a ciertas órdenes monásticas como Cluny o el Císter, colaborando así con la reforma espiritual. Pero también financiaron la construcción de monasterios ex novo en los que introdujeron el Císter, principalmente ${ }^{11}$.

Tomaremos como referencia a los Muñoz, una parentela establecida en el Campo de Toro en el siglo XI como muestra de este proceso de construcción de monasterios particulares y entrega a una orden monástica ${ }^{12}$. Pero también porque uno de sus miembros, Fernando Fernandes de Toro es al mismo tiempo un Bragança. Su enlace con la hija de Alfonso VI le convertirá en un personaje muy destacado que sirve de enlace a ambos lados de la frontera a principios del siglo XII, pues este matrimonio es el germen de los Cabrera y Ribera.

El origen de los Muñoz es el conde Munio Rodríguez, establecido en el Campo de Toro desde la caída del Califato. En 1042, su hijo Oveco Muñoz y su esposa Marina Vímaraz, junto a sus hijos, fundan el monasterio de San Salvador de Villacete, sito en la actual localidad zamorana de Belver de los Montes. Los fundadores entregan todas las heredades que habían ganado y aumentado, además del realengo y comisso de Villacete, que les había concedido Vermudo III de León. El documento es muy elocuente, tras un amplio preámbulo, relatan que habían edificado el monasterio: Construximus ibidem monasterium et ecclesiam Sancti Saluatoris et terminis et limitibus per circuitu. En él se integraba el cementerio, donde posiblemente sería enterrado Munio poco después. Además, la pareja justifica los motivos de la realización de su obra: Et Domino protegente edificauimus claustra fr[atrum ... in] nocentum et sancte castimonie diligentium et de opera manuum nostrarum deferimus fratribus his alimonie uictum ${ }^{13}$.

Los herederos del monasterio tuvieron ciertos conflictos sobre sus porciones, como el que enfrentó a Fronilde Ovéquiz, hija de Oveco, con Marina, la segunda esposa de su padre. Para resolverlo se reunieron en el propio monasterio, como indica Fronilde, junto a sus parientes y otros hombres buenos: fuimus proinde ic in cenouio Sancti Saluatoris, que est fundato en Uale de Uila Ceide et ibi erant nostras gens et multos omines bonos ${ }^{14}$. Los

monasterios particulares de la aristocracia altomedieval leonesa». Anuario de Estudios Medievales, 2012 , vol. 42, n. 2 , pp. 799-822.

${ }_{11}$ Véase Cavero Domínguez, Gregoria. El esplendor del Císter en León. León: Fundación Hullera vasco-leonesa, 2007, pp. 73-108. Alonso Álvarez, Raquel. «Los promotores de la Orden del Císter en los reinos Castilla y León». Anuario de Estudios Medievales, 2007, vol. 37, n. o 2, pp. 653-710.

12 El fundador de la parentela es el conde Munio Rodríguez, casado con la condesa Adosinda. Su hijo el conde Fernando Muñoz, fue partidario de Vermudo III hasta 1034 cuando cambia de fidelidad para servir a Fernando I. En 1040 fue tenente de Toro y Astorga y posteriormente también de Zamora y Sanabria, aunque en 1048 se enfrentó a Fernando I, muriendo poco después. Su hermano era Oveco Muñoz, fundador de San Salvador de Villacete, murió en 1043. Tras la muerte del conde Fernando Muñoz, la familia fue apartada del gobierno del Campo de Toro hasta que en 1062 Fernando I entregó la tenencia de Toro a Munio Fernández, hijo del conde Fernando. Véase esquema genealógico I.

13 Herrero de la Fuente, Marta. Colección Documental del Monasterio de Sahagún. Tomo II (10001073). León, Centro de Estudios San Isidoro, 1998, doc. 473.

14 El diploma está datado en 1029 aunque algunas hipótesis indican que el escriba olvidó la X aspada, por lo que habría que datarlo en 1059. Herrera de la Fuente, Colección, doc. 424. 
PETRIFICANDO LA RIQUEZA FAMILIAR MÁS ALLÁ DE LA FRONTERA. LA CONSTRUCCIÓN COMO ELEMENTO DE CREACIÓN DE IDENTIDAD Y MEMORIA NOBILIARIA ENTRE LEÓN Y PORTUGAL INÉS CALDERÓN MEDINA

litigios continuaron entre los herederos de Oveco y Marina, hasta que Fronilde donó su porción al monasterio de Sahagún en $1103^{15}$.

Es, al parecer en ese momento, cuando, según Charles García, se incorpora en el documento fundacional de 1042, una miniatura en la que se representa a Oveco Muñiz y a Marina, arrodillados frente a Cristo en majestad y junto al primer abad sentado, siendo testigo del acto. Es uno de los pocos ejemplos de diplomas miniados en el siglo XI y principios del XII. Afirma que la miniatura fue elaborada posiblemente en el scriptorium de Sahagún. En ella los fundadores están arrodillados y alargando sus brazos hacia el Señor, lo que simboliza la ofrenda de su monasterio, además su expresión facial transmite gran felicidad. García atribuye a esta miniatura una función didáctica, propagandística, destinada a los herederos de los fundadores en el momento en el que entregaban sus porciones a Sahagún ${ }^{16}$. En ella se vincula claramente a Oveco y María con la fundación y construcción del monasterio de San Salvador de Villacete, que relata el diploma. Así, se pretendía tener en la memoria a los fundadores y constructores de San Salvador, a quienes se integra en las oraciones por la salvación de sus almas en Sahagún, aunque sus cuerpos no descansaran en el monasterio ${ }^{17}$

La otra línea de descendencia de esta parentela, representada por el conde Fernando, hermano de Oveco, será quien conserve el poder en el Campo de Toro. El conde Fernando murió en 1048, enfrentado a Fernando I. El rey apartó a la familia del gobierno de esta tierra hasta 1062, cuando entregó la tenencia a su hijo Munio Fernández, quien casaría con Aldonza Gómez. Aldonza ya tenia un hijo llamado Fernando Fernandes de Toro $^{18}$, quien, según Ferreira do Amaral es hijo del tenente de Chaves Fernando Mendes de Bragança $(\mathrm{I})^{19}$, que permaneció en la corte de Alfonso VI y después de su hija Urraca, quien le entregaría en 1117 las tenencias de Zamora y Toro. Así, comienzó a extenderse el poder de los Bragança en este espacio zamorano.

15 Acerca del proceso de entrega de las distintas porciones del monasterio y de los enfrentamientos entre el grupo de parientes, véase. García, Charles, "La territorialisation du Campo de Toro au Moyen Âge (IX-XI ${ }^{\text {̀̀me }}$ siècles)». Pandora: revue d'etudes hispaniques, 2010, vol. 10, pp. 17-32. García, Charles. Le Campo de Toro au Moyen Âge. Peuplement, seigneuries et société (IX - XIV siècles). Paris: Atélier National de Reproduction de théses, 2002, vol. 1, pp. 175-184. Sobre los Muñoz, véase Reglero de la Fuente, Carlos. Los señoríos de los montes Torozos: de la repoblación al Becerro de las behetrías (siglos X-XIV). Valladolid: Universidad de Valladolid, 1993, pp. 171-172. Calderón Medina, Los Soverosa, pp. 55-63.

${ }_{16}$ García, Charles. «El magnate, la mujer y el abad. Iconografía y memoria de los antepasados en el territorio de la actual Zamora». Studia Zamorensia. Segunda Etapa, 1999, vol. 5, pp. 9-22, pp. 14-16. Los nietos de Fronilde, los Captivi, aún mantenían una parte de la porción de su padre, Pedro Peláez, en la primera mitad del siglo xII, cuando lo entregaron a Sahagún. Calderón Medina, Los Soverosa, pp. 61 y ss.

17 García, «El magnate», pp. 20-22.

18 La identificación de Fernando Fernández de Toro ha suscitado distintas hipótesis. Martínez Sopena lo identificó como hijo de Fernando Muñoz. Martínez Sopena, "Aristocracia, monacato y reformas», p. 80. Calderón Medina, Inés y Ferreira Martins, João Paulo. «Os senhores de Cabreira e Ribeira. Um estudo sobre a sua origen e transcendencia peninsular, (séculos XII-XIV)». Revista Portuguesa de História, 2013, vol. 44, pp. 123-152, p. 132

19 Se trata del tenente de Chaves en 1084. Durante ese año permaneció al servicio de Alfonso VI y, probablemente, participó en la conquista de Toledo. Permaneció en su corte y en la de su hija hasta 1118. Ferreira do Amaral, «A linhagem dos Bragançãos- Parte I», pp. 269-288. 
PETRIFICANDO LA RIQUEZA FAMILIAR MÁS ALLÁ DE LA FRONTERA. LA CONSTRUCCIÓN COMO ELEMENTO DE CREACIÓN DE IDENTIDAD Y MEMORIA NOBILIARIA ENTRE LEÓN Y PORTUGAL INÉS CALDERÓN MEDINA

Durante la vida de su padre Fernando Fernandes de Toro, (o de Bragança I) ${ }^{20}$, casó con Elvira Alfonso, la hija que Alfonso VI había tenido con la noble berciana Jimena Mu$\tilde{n i z}^{21}$, hermana entera de la condesa Teresa de Portugal. El matrimonio probablemente se estableció en 1111, cuando Fernando se trasladó a Portugal al servicio del conde Enrique. Ese año sería tenente de Lamego. Posteriormente, cambió de fidelidad, poniéndose al servicio de Urraca, que le entregó las tenencias de Toro y Benavente, entre otras, hasta $1124^{22}$. Su hija, Teresa Fernández, casaría con el conde Osorio Martínez, hijo del conde leonés Flaín Muñoz, extendiendo así su influencia a la Tierra de Campos ${ }^{23}$.

Mientras, el hermano de Fernando Fernandes de Toro, Mendo Fernandes permaneció en Bragança, de la que pudo haber sido tenente. Sus hijos Fernando, Rodrigo, Nuno y Mendo Mendes de Bragança ${ }^{24}$, serían quienes ostentarían el poder en la segunda mitad del siglo XII, especialmente Fernando Mendes de Bragança, (II), «el Bravo» y Mendo, que se alternaría en la tenencia de Zamora y Sanabria con Ponce de Cabrera ${ }^{25}$. Es en este contexto en el que probablemente, según Pizarro, él o sus hermanos promovieron el establecimiento del monasterio de Castro de Avelães, a partir de la década de los años treinta, cuando apoyan a Alfonso Enríquez ${ }^{26}$.

La implantación de los Cabrera en Zamora y Sanabria se inició en 1129, cuando Alfonso VII le entregó la tenencia de la ciudad de Zamora a Ponce de Cabrera, el magnate catalán que acababa de llegar a León acompańando a la nueva reina, Berenguela de Barcelona. Ponce, intitulado Princeps Çemore la tendría hasta 1159. Además, fue tenente de Sanabria, desde 1132 hasta 1158, y en 1138 de Cabrera; de Toro en 1158 y Benavente en 1159. Asimismo, poseía un enorme patrimonio en Manganeses de Lampreana, San Pedro de Ceque, Trefacio y Galende, Castro Toraf y Moreruela ${ }^{27}$. No resulta extrańo que los Cabrera y los Bragança emparentaran pronto, pues ambas parentelas tenían intereses en Zamora y Sanabria.

Es entonces cuando se aprecia en este territorio en el que se está dibujando la frontera tras el Tratado de Zamora de 1143, una gran actividad constructiva, financiada en

20 Seguimos la identificación, que estimamos adecuada, de Ferreita do Amaral.

21 Jimena Muñiz era hermana de Pedro Muñiz, el primer tenente de las tierras de Cabrera y Ribera.

22 Barton, Simon. The aristocracy in twelfh-century Leon and Castile. Cambridge: Cambridge University Press, 1997 , pp. 236-237.

23 Calderón Medina y Ferreira Martins, «Os senhores», pp. 132-136.

24 Ferreira do Amaral, "A linhagem dos Bragançáos- Parte I», pp. 292-299

25 Fue tenente de Bragança en 1129 de mano de Alfonso Enríquez y en 1131 y 1136 tendría Zamora. Posteriormente regresaría a la corte lusa, donde se le documenta gasta 1155-57. Casó primero con Teresa Soares de Maia y, en torno a 1147, con la hermana de Alfonso Enríquez, dońa Sancha. Ferreira do Amaral, "A linhagem dos Bragançãos- Parte I», pp. 294-298.

${ }_{26}$ Sottomayor Pizarro, José Augusto. «A aristocracia no territorio de Bragança, (séculos XI-XV)», En da Fonseca, Luis Adão, et al. Bragança na Idade Média. Bragança: Munícipio de Bragança, 2019, pp. 177-209, pp. 181-183. Véase esquema genealógico II.

27 Véase, Fernández Xesta. Ernesto. Un magnate catalán en la corte de Alfonso VII. Comes Poncius de Cabreira, princeps Çemore. Madrid: Prensa y Ediciones iberoamericanas, 1991. 
PETRIFICANDO LA RIQUEZA FAMILIAR MÁS ALLÁ DE LA FRONTERA. LA CONSTRUCCIÓN COMO ELEMENTO DE CREACIÓN DE IDENTIDAD Y MEMORIA NOBILIARIA ENTRE LEÓN Y PORTUGAL INÉS CALDERÓN MEDINA

gran medida, por estas dos parentelas nobiliarias. Promueven importantes monasterios, que tendrán un destacado papel en la organización del espacio ${ }^{28}$.

En 1143, Alfonso VII donaba a su mayordomo Ponce de Cabrera la villa diu desertam de Moreruela, y a través de él a los monjes Pedro y Sancho, para que en ella edificaran un monasterio bajo la Regla de San Benito ${ }^{29}$. Posiblemente en la aldea había existido un cenobio, pero 1143 representa una nueva etapa de vida monástica benedictina, en la que se comenzó a construir el monasterio que, entre 1158 y 1163 , se entregó al Císter ${ }^{30}$.

Casi simultáneamente, en 1150, su hija Sancha Ponce fundará ex novo junto a su esposo, Vela Gutiérrez, el monasterio particular benedictino femenino de San Esteban de Nogales, que, en 1163, entregará a los monjes blancos. Asimismo, en 1150 el sobrino del conde Ponce, Pedro Cristiano, introduce el Císter en San Martín de Castañeda ${ }^{31}$. Mientras, al otro lado de la frontera, los Bragança estaban construyendo Castro de Aveláes.

Durante la segunda mitad del siglo XII, el gasto de los Cabrera en la promoción de estos grandes edificios es ingente. A las propiedades entregadas en las cartas fundacionales, los hijos y nietos del conde Ponce de Cabrera irán donando para la consolidación de sus dominios, las porciones que aún tenían en las aldeas de la que el Conde había entregado una parte. En el monasterio de Moreruela, el $50 \%$ de las donaciones hasta 1270 fueron efectuadas por los descendientes del fundador, mientras que en San Esteban de Nogales representan un 75\%; lo que muestra la gran aportación patrimonial de la parentela fundadora ${ }^{32}$. Si se analizan las donaciones realizadas por el conde Ponce y sus descendientes, hasta la cuarta generación, se puede observar además el proceso constructivo de Moreruela.

Es posible que las obras ya estuvieran avanzadas en 1156, cuando en un pacto entre el monasterio y la villa cercana de Castrotoraf, se denomina al conde Ponce constructori Morerole, destacando claramente su relación con el monasterio, situado a doce kilóme$\operatorname{tros}^{33}$.

La datatio de la construcción de la Iglesia de Moreruela es $1162^{34}$. Al parecer, en 1181 ya estaría construída la cabecera de la iglesia, donde su sitúa la capilla en la que

28 Oliveira, Carlos. «O mosteiro beneditino de São Salvador de Castro de Avelãs no povoamento da regiāo bragançana». Brigantia,1991, vol. XI, 1-2, pp. 33-46.

29 Alfonso Antón, Isabel. La colonización cisterciense de la Meseta del Duero. El dominio de Moreruela (siglos XII-XIV). Zamora: Instituto de Estudios Zamoranos Florián Ocampo, 1986, doc. 4.

30 Acerca de la controversia historiográfica sobre la fecha de introducción del Císter en el monasterio véase. Calderón Medina, Inés. «El impulso nobiliario a la expansión del Císter en el Reino de León. La parentela de Ponce de Cabrera en los monasterios de Santa María de Moreruela y San Esteban de Nogales». Medievalismo, 2008, vol. 18, pp. 344-371, pp. 346-354.

31 Sobre el papel del monasterio en la feudalización de Sanabria y el apoyo de la monarquía entre 1150-1200, Martín Viso, Ińaki. "La feudalización de valle de Sanabria, siglos X-XIII». Studia Historica. Historia Medieval, 1993 , vol. 11, pp. 33-55, pp. 49-53.

32 En el caso de Moreruela, 11 de las 27 donaciones realizadas hasta 1270 son efectuadas por descendientes del conde, mientras que en Nogales son 7 de las 11 recibidas por el cenobio. Calderón Medina, «El impulso nobiliario", p. 360

33 Alfonso Antón, La colonización, doc.9.

34 Miguel Hernández, Fernando. «Aproximación arqueológica al monasterio de Santa María de Moreruela». Anuario del Instituto de Estudios Zamoranos Florián Ocampo, 1994, vol. 11, pp. 56-76, p. 63. 
PETRIFICANDO LA RIQUEZA FAMILIAR MÁS ALLÁ DE LA FRONTERA. LA CONSTRUCCIÓN COMO

recibió sepultura el nieto del conde, Juan Vela, hijo de Sancha Ponce y Vela Gutiérrez. Entonces, sus hermanos donan sus propiedades en San Pedro de Ceque, Galende y lo que habían heredado de su abuela Toda Pérez de Traba ${ }^{35}$, al monasterio para la salvación del alma de Juan.

Entre los hijos de Sancha Ponce, además de Fernando, Pedro y Poncio, figura Suero Menéndez, el hijo que Sancha había tenido de su segundo matrimonio con Mendo de Bragança, hijo de Mendo Fernandes de Bragança (II) ${ }^{36}$. El esposo de Sancha había sido alférez de Alfonso Enríquez hasta 1148. A partir de 1152 aparece en León donde ocupa la alferecía hasta 1161, además de la tenencia de Sanabria, que se alternaba con su suegro $^{37}$. Así aumentó el poder de los Bragança en este espacio y su vinculación con San Martín de Castañeda y Moreruela.

A partir de las últimas décadas del siglo XII y primera mitad del XIII se observa una mayor intensidad en la construcción del monasterio, con la aportación de Alfonso IX ${ }^{38}$, de los descendientes de Ponce de Cabrera ${ }^{39}$ y del apoyo de los Bragança y sus vasallos, que comienzan a hacer donaciones a Moreruela, que extiende su dominio al territorio brigantino.

Al mismo tiempo, los hermanos e hijos de Sancha Ponce van donando las porciones que tenían en San Pedro de Ceque y Granucillo al monasterio de Nogales hasta $1264^{40}$, financiando así la obra del centro fundado por Sancha y Vela Gutiérrez.

Es el periodo entre la década de los noventa del siglo XII y la de los treinta del siglo XIII, cuando las fuentes translucen un aumento de la actividad constructiva. En este tiempo coinciden en el escenario los homónimos Fernando Fernandes de Bragança y

35 Alfonso Antón, La colonización, docs. 21 y 22. Ambos documentos están fechados el 7 de diciembre de 1181 .

36 Era hijo de Fernando Mendes de Bragança, pero se desconoce si de su primer matrimonio o del segundo con la infanta Sancha Enríquez, hermana de Alfonso Enríquez. El Livro Velho, informa de su primer matrimonio con Gontinha Soares de Maia pero ninguna de las obras genealógicas portuguesas menciona su enlace con Sancha Ponce. Su descendencia destacada en el Livro Velho, utiliza la onomástica Ponce, lo que le vincula con los Cabrera. Sobre la trayectoria del magnate véase. Calderón Medina y Martins Ferreira, «Beyond the border»; Calderón Medina, Inés. Cum magnatibus regni mei. La nobleza y la monarquía leonesas durante los reinados de Fernando II y Alfonso IX de León (1157-1239). Madrid: CSIC, 2011, pp. 202-205. Ferreira do Amaral, «A linhagem dos Bragançãos- Parte I», pp. 289-290.

37 Durante la década de los 50 el conde Ponce y Mendo se alternan en la tenencia. Rodríguez González, Ángel. El Tumbo del monasterio de San Martín de Castañeda. León: Centro de Estudios San Isidoro, 1973, docs. 27-42.

38 El rey exime de pecho, petito y facendera a la heredad de Carballeda, cuyos vasallos estaban probablemente obligados a trabajar en la obra de Moreruela. Alfonso Antón, La colonización, doc. 36, p. 234.

39 Alfonso Antón, La colonización, docs. 40, 41

40 En 1209, Fernando Fernández, con la autorización de sus sobrinos (hijos de sus primos) Juan Fernández y Pedro Ponce, vende al abad de Nogales lo que les correspondía en San Pedro de Ceque por 1700 maravedíes. En 1264, Aldonza Alfonso, viuda de Pedro Ponce de Cabrera dona lo que su esposo le había entregado en arras en la villa. Cavero Domínguez, Gregoria. Colección documental del monasterio de San Esteban de Nogales (1149-1498). León: Centro de Estudios San Isidoro, 2001, docs. 33 y 96. Las heredades de Granucillo fueron entregadas por los hijos de Sancha Ponce entre 1195 y 1198. En 1195, Ponce Vela y su esposa, donaron la tercera parte de la villa al abad de Nogales. En 1198 su primo Fernando Fernández, hijo de Fernando Ponce donó su porción. Cavero Domínguez, Colección, docs. 22 y 25. 
PETRIFICANDO LA RIQUEZA FAMILIAR MÁS ALLÁ DE LA FRONTERA. LA CONSTRUCCIÓN COMO ELEMENTO DE CREACIÓN DE IDENTIDAD Y MEMORIA NOBILIARIA ENTRE LEÓN Y PORTUGAL INÉS CALDERÓN MEDINA

Fernando Fernández de Cabrera ${ }^{41}$. En un diploma, datable entre 1204-1215, se copian varias donaciones destinadas a la obra de Moreruela. Tal vez, se pretendía tener una cierta contabilidad de los bienes y recursos con los que contaba. Los donantes son Fernando Fernández de Cabrera y su mujer María Pérez y, sus padres el conde Fernando Ponce, «el menor» y su esposa, Estefanía López ${ }^{42}$. Es probable que las donaciones que se copian en este diploma se realizaran tras un encuentro entre cada uno de los Cabrera con el abad del monasterio y el maestro de obra; pues destacan que las hicieron cum consilio magistri opera.

Es probable que la primera donación se efectuara entre 1204 y 1209 , pues en ese tiempo Fernando Fernández de Cabrera y su esposa María Pérez donan también San Pedro de Cete a San Esteban de Nogales ${ }^{43}$. El matrimonio hace un pacto con el abad y con el maestro de obra, por el que entregaban ad edificacionem ecclesie Beate Marie Virginis de Morerola: CCC aureos et singulis annis centum, $L X$ vacas, $C$ oves et singulis annis decimam anone tocius agriculture nostre, y su heredad de Figuerola. Fernando deseaba que si su mujer le sobrevivía, los réditos de esa villa los tuviera el monasterio y los emplease in usus fabrice ecclesie. Pero además de estos ingresos, la pareja se preocupa por el aprovisionamiento de la madera necesaria para la construcción, al donar al monasterio su silva de Parada, facte transeant ad operam Beate Marie, y la villa de Villa Nova Sicca opus ecclesie petrificatur ${ }^{44}$.

Para la obra donan la heredad de Pajares y las tierras que tenían en la ribera del Esla, al lado de las aceñas nuevas, para construir un canal que garantizara el agua y el pescado al cenobio. Así, se estableció un acuerdo entre el cellero del monasterio y el maestro de la obra para la construcción del canal, de manera que el monasterio se quedara con la quinta parte del pescado y el maestro de obra con la sexta. Los beneficios de este pescado debían ser empleados en la petrificación de la iglesia ${ }^{45}$. También garantizaron el avituallamiento del ganado empleado en la obra, donando un prado en el que pastara ${ }^{46}$. Al final de esta carta, el abad Pelayo bajo pena de excomunión e interdicto prohibe que nullus sine

41 Su homonimia en ocasiones puede llevar a la confusion, dado que ambos tienen una vinculación estrecha con Moreruela, Bragança y San Martín de Castañeda. Sobre su trayectoria véase Calderón Medina, Cum magnatibus regni mei, pp. 218-226. Calderón Medina y Ferreira Martins, "Beyond the border».

${ }_{42}$ Este diploma ha destacado recelos. Isabel Alfonso considera que podría datarse entre 1204 y 1215 , aunque propone la fecha de 1204 . Ferreira de Amaral, estima que el protagonista es Fernando Fernandes de Bragança, Ferreira do Amaral, "A linhagem dos Bragançãos- Parte I», pp. 302-304. Pero desconoce los documentos en los que Fernando Fernández de Cabrera y su esposa María Pérez donan a San Esteban de Nogales la villa de San Pedro de Ceque, que había tenido su abuelo Ponce de Cabrera; de modo que consideramos que, queda probado, que el protagonista de estas donaciones es Fernando Fernández de Cabrera.

43 Cavero Domínguez, Colección, doc. 33: Quia propter ego Fernandus Fernandi et uxor mea María Petri cum au[toritatem] nepotum meorum scilicet Iohannes Fernandi et Petrus Poncii uobis dompno Michaeli, monasterii sancte Marie de Nogales abbati, et omnibus fratribus eiusdem loci tam presentibus quam futuris [facimus cartam] uendicionis et firmitudinis de omni nostra hereditate quam habemus uel habere debemus et auus noster comes Poncius adquisiuit a domino Adefonso imperatore. El matrimonio firma en 1230 otra donación de San Pedro de Cete. Cavero Domínguez, Colección, doc. 52.

44 Alfonso Antón, La colonización, doc. 48

45 Et hoc tandiu fiat donec opus ecclesie petrificatur. Alfonso Antón, La colonización, doc. 48

46 Damus dicto operi quoddam pratum ad pascendam peccora eiusdem operis. 
PETRIFICANDO LA RIQUEZA FAMILIAR MÁS ALLÁ DE LA FRONTERA. LA CONSTRUCCIÓN COMO

licentia magisteri opera scienter de substancia eiusdem operis accipiat, nec ego Pelagius, dictus abbas Morerola, nec aliquis de monasterio sive monachus, vel conversus, vel laicus.

A continuación se copian ciertas donaciones que parecen ser efectuadas por los padres de Fernande Fernández, el conde Fernando Ponce, «el menor», y su esposa Elvira López $^{47}$, con anterioridad a 1200 . Entregan para la obra de la Iglesia la villa de Cional ${ }^{48}$, y operi illa, la heredad de Moreruela de Miro y Villalpando ${ }^{49}$. Tal vez tras el fin de su matrimonio, la condesa Estefanía donó en solitario, para la obra de Moreruela, dos casas que ella misma había mandado hacer y costeado ${ }^{50}$.

Este diploma muestra, además del patrimonio entregado, el diálogo habitual con el jefe de obra y la preocupación de la parentela fundadora por la construcción del cenobio, que se convirtió en el principal lugar de creación de su identidad y memoria. Aunque algunos de los parientes eligieron como última morada Nogales, Vela Gutiérrez y su esposa Sancha Ponce en 1176, o su nieto Pedro Pérez Ponce, sepultado en la capilla de San Benito ${ }^{51}$. En Moreruela fueron enterrados Juan Vela en la capilla de San Juan y su sobrino Fernando Ponce, hijo de Ponce Vela. Pero aún cuatro generaciones después de la fundación de Ponce de Cabrera, su bisnieto Fernando Pérez Ponce, hijo de Pedro Ponce de Cabrera y Aldonza Alfonso, recibió sepultura junto a su esposa al lado de los Evangelios, dentro de la capilla mayor de la iglesia del monasterio ${ }^{52}$. Un lugar privilegiado para este miembro de la familia, nieto de Alfonso IX de León.

Pero además de los Cabrera, también se registran algunas donaciones de sus vasallos como Mendo Rodríguez, que con anterioridad a 1233 había donado varios bienes para la construcción del claustro ${ }^{53}$. En 1238 Martín Peláez y Pedro López donaron una pedrera de la que se sacaría la piedra para la construcción del monasterio, en presencia del maestro de obra, que confirma la carta ${ }^{54}$.

No obstante, en la primera mitad del siglo XIII los Bragança también hicieron grandes aportaciones a Moreruela. Fernando Fernandes de Bragança donó la heredad de Infães que había recibido de Alfonso $\mathrm{IX}^{55}$, y a la que el abad dio fuero en 1220. En el fuero,

47 Fernando Ponce el menor, era hijo de Ponce de Cabrera y María Fernández de Traba. Recibió la dignidad condal en 1184. Casó con anterioridad a 1200 con Estefanía López de Haro, hija de Lópe Díaz de Haro. El matrimonio fue disuelto antes de 1200. Fernández- Xesta, Un magnate, p. 73.

48 El diploma dice Damus etiam dicto operi villam nostram que dicitur Zeonal cum ecclesie eiusdem villa, sicut Fernandus Fernandi teneat eam de nobis cum iure sui, lo que hace pensar que no es Fernando Fernández de Cabrera quien otorga la donación, además a continuación se copia una donación de la condesa Estefanía López.

49 La condesa Estefanía, tras la muerte del que fue su esposo, hace una donación a Moreruela en 1215. Alfonso Antón, La colonización, doc. 48.

50 Ego comitissa dona Estevania doo et concedo bono animo et expontanea voluntate operi Beate Marie de Morerola domos illas quas feci propris sumpibus que sunt iuxta ortum ubi sunt piraria que vocatur pira de cano; Alfonso Antón, La colonización, doc. 71

51 Cavero Domínguez, Colección, doc. 96.

52 De Yepes, Antonio. Crónica General de la Orden de San Benito. Valladolid: Fernández de Córdova, 1617. Calderón Medina, «El impulso nobiliario», pp. 365-366.

53 Alfonso Antón, La colonización, doc. 93.

54 Alfonso Antón, La colonización, doc. 98.

55 Alfonso Antón, La colonización, doc. 67. 
PETRIFICANDO LA RIQUEZA FAMILIAR MÁS ALLÁ DE LA FRONTERA. LA CONSTRUCCIÓN COMO ELEMENTO DE CREACIÓN DE IDENTIDAD Y MEMORIA NOBILIARIA ENTRE LEÓN Y PORTUGAL INÉS CALDERÓN MEDINA

se reserva las tercias propter opus dictus ecclesie ${ }^{56}$. Don Fernando donó la mitad de la villa de Braceosa ${ }^{57}$, Santa María de Vilabona ${ }^{58}$ y su parte de Vimioso, entre otras. Pero también entregó otras propiedades al monasterio de San Martín de Castañeda, como una parte de Angueira ${ }^{59}$, y numerosas propiedades a Castro de Avelães.

Sus vasallos, como Pedro Menéndez Tyo, también entregaron sus heredades en tierra de Miranda a Moreruela ${ }^{60}$, como la de Palaçoulo que dona por las almas de su padre y de Fernando Fernandes de Bragança, su señor y tenente de Bragança en mayo de 1224 cuando se otorga la carta ${ }^{61}$. Pero la vinculación de Pedro Tyo no sólo fue con el monasterio de Moreruela, sino también con el de Castro de Avelães, como sus señores los Bragança ${ }^{62}$.

Otro miembro de la nobleza media también vinculado a los Bragança es Alfonso Mendes de Bornes, hijo de Mendo Bofim ${ }^{63}$, el constructor del castillo de Ulgoso. Estando entre los muros del monasterio, le donó todos los bienes que tenía en el territorio de Miranda, en las aldeas de Genicio y San Juan de la Ribera. Poco tiempo después, en febrero de 1256, estando, junto al abad de Moreruela, en la Iglesia de Santa María de Bragança, donó lo que tenía en otras aldeas del término de Miranda al monasterio en el que pedía ser sepultado e instituyó un aniversario ${ }^{64}$.

De este modo, Alfonso Mendes estaba colaborando con el monasterio que pretendía hacerse con toda la propiedad de la villa de Angueira para financiar, en gran medida, la obra de su Iglesia. En 1257 el abad Guterius dio fuero a la villa; dos de sus disposiciones son de gran importancia para la construcción del monasterio. En ellas, el abad se reserva

56 Alfonso Antón, La colonización, doc. 75.

57 PMH, INQ 1258,1282 a.

$58 \mathrm{PMH}$, INQ 1258, 1306b.

59 PMH, INQ 1258,1283 b.

60 Alfonso Enríquez le donó en 1172 el realengo de Palaçoulo, en Ulgoso, y varias villas con potestad para construir concedimus vobis ut ubicumque volueritis ponatis villas vestras et sedes vestras construatis. Alfonso Antón, La colonización, docs. 17 y 18.

${ }_{61}$ Alfonso Antón, La colonización, doc. 78. Lo otorgan Pedro Pérez, su esposa Sancha y lo firman también sus hijos Pedro Pérez y María Pérez. Confirma la carta Fernando Fernandes de Bragança y el prior de Moreruela. Uno de los testigos de las inquiriçôes de 1258 confirma esta donación scit quod fratres de Moreyrola impetrauit uilla de Palaciolo in Miranda de Petro Tyo, in tempore Regi Sancii, fratris istius, interrogatus unde habuit eam Petrus Tyo, dixit quod nesciebat; PMH, INQ 1258, 1283 b. Este Pedro Tyo ya habría fallecido en 1258, pues uno de los testigos de la parroquia de Santa María de Serzedo así lo confirma. Narra que en esa parroquia tenía medio casal que tras su muerte tenía Nuno Chacim que lo entregó a Castro de Avelães; PMH, INQ 1258, 1318a.

${ }_{62}$ Antes de morir entregó al monasterio lo que tenía en la parroquia de San Miguel de Spadamedo; PMH INQ 1258, 1323a: scit quod monasterium Crasto Auellanarum impetrauit II casalia in ipsa villa de Petro Tyo et domna Chamoa.

63 En 1255 en el propio monasterio de Moreruela dona lo que tiene en Genicio y San Juan de la Ribeira que eredey de Meen Bofino. Alfonso Antón, La colonización, doc. 136.

${ }_{64}$ Alfonso Antón, La colonización, docs. 137 y 142. Pero sólo unos meses después terminaría de entregar al monasterio de Moreruela lo que le quedaba en Genicio y San Juan de Angueira, por el precio simbólico de una mula. Estas donaciones tienen su reflejo en las inquiriçóes, pues los testigos afirman que en los últimos tres años había entregado las tercias a Moreruela; PMH, INQ 1258, 1271b. Don Alfonso tenía propiedades en otras aldeas en tierra de Miranda, como de Santa María de Bornes, en San Martín de Travanca, y en San Vicente de Vall de Porcas; PMH, INQ 1258, 1307a,1307 b, 1309 b, 1314 b. 
PETRIFICANDO LA RIQUEZA FAMILIAR MÁS ALLÁ DE LA FRONTERA. LA CONSTRUCCIÓN COMO

una tercera parte del tributo de mañería y una tercera parte del tributo de algaravitate, que se emplearán detur ecclesie propter opus ipsius ecclesie ${ }^{65}$.

Además de Moreruela, los Bragança tuvieron estrechas relaciones con San Martín de Castañeda en Sanabria y con el monasterio de Castro de Avelães, que habían mandado construir, aunque no se conserva documentación de este proceso. El cenobio benedictino es un ejemplo excepcional, pues se trata del único monasterio construido en ladrillo en el actual territorio portugués.

Aunque pudo existir un edificio anterior ${ }^{66}$, Pizarro señala que la actual construcción pudo haberse promovido por parte de Fernando Mendes de Bragança (II), o sus hermanos, a partir de la década de los años treinta del siglo XiI ${ }^{67}$. En 1145 Alfonso Enríquez efectuó una donación al monasterio, apoyando así el fortalecimiento de esta casa que habría fundado su cuñado. Desde entonces, la vinculación de los Bragança con el cenobio fue estrecha hasta que en 1199 lo afilian a San Martín de Castañeda ${ }^{68}$.

Mucho se ha discutido acerca de la excepcionalidad de este monasterio por su material de construcción ${ }^{69}$. Los Bragança tenían una gran capacidad económica como para edificar un monasterio en piedra, por lo tanto, considero que la elección de realizar una construcción en ladrillo debe de tener alguna motivación simbólica, que se nos escapa. Al parecer, el plan inicial de la iglesia era monumental: se trataba de una construcción de tres naves y dos torres a cada lado del cuerpo central; pero, según algunos especialistas, no llegó a terminarse ${ }^{70}$. Sin embargo, ciertos vestigios permiten afirmar que la iglesia se terminó y se construyó el claustro en ladrillo ${ }^{71}$. En la actualidad sólo se conserva la capilla mayor y los absidiolos ${ }^{72}$. Estilísticamente pudo tener una gran afinidad con la iglesia de San Tirso de Sahagún ${ }^{73}$, aunque no hay testimonios de la conclusión de la torre, pero también pudo tener ciertas semejanzas con iglesias de Toro $^{74}$.

Valdés Fernández señala que la promoción de iglesias en estilo mudéjar entre los siglos XI y XIII es un fenómeno propio de la monarquía en León y Castilla y más tardío entre el estamento nobiliar ${ }^{75}$. Esta afirmación nos lleva a plantear la hipótesis de que los Bragança promocionaran la construcción del cenobio, que era la referencia para la

65 Alfonso Antón, La colonización, doc. 144.

${ }_{66}$ da Fonseca et al. Bragança na Idade Média, pp. 306-307.

${ }_{67}$ Sotomayor Pizarro, «A aristocracia no territorio», pp. 182-183.

68 Soares Machado, Os Bragançāos, pp. 145-148

${ }^{69}$ da Fonseca et al. Bragança na Idade Média, pp. 303-306.

70 Ferreira de Almeida, Carlos Alberto. História da Arte em Portugal. O románico, Lisboa: Presença, 2001, vol. 2, p. 126 y vol. 3, p. 104.

71 Almeida Fernandes ha consultado las memorias de excavación que permanecen inéditas y recoge sus resultados. Almeida Fernandes, Paulo. «Castro de Avelâs: o estranho caso de uma igreja de tijolo». Monumentos: revista semestral de edificios e monumentos, 2011, vol. 32, pp. 84-95, p. 89. nota 14.

72 Externamente está decorada con arcadas ciegas.

73 Ferreira de Almeida, História, vol. 2, p. 126.

74 Almeida Fernandes, «Castro de Avelâs», p. 92. Valdés Fernández, Manuel. La Arquitectura mudéjar en León y Castilla. León: Universidad de León, 1984, pp. 102-117 y pp. 161-182.

75 Valdés Fernández, Manuel. «Arquitectura mudéjar y los sistemas constructivos en León y Castilla en torno a 1200». En Lacarra Ducay, M. ${ }^{a}$ del Carmen (coord.). Arquitectura mudéjar en Aragón, León, Castilla, Extremadura y Andalucía. Zaragoza: Institución Fernando el Católico, 2006, pp. 65-110, pp. 84-87. 
PETRIFICANDO LA RIQUEZA FAMILIAR MÁS ALLÁ DE LA FRONTERA. LA CONSTRUCCIÓN COMO ELEMENTO DE CREACIÓN DE IDENTIDAD Y MEMORIA NOBILIARIA ENTRE LEÓN Y PORTUGAL INÉS CALDERÓN MEDINA

construcción de su identidad, como un modo de vincularse a la monarquía y a la figura de Alfonso VI, con el que habían emparentado a través del matrimonio de Fernando Fernandes de Toro y la infanta Elvira. De hecho, su parentesco con la monarquía será el recurso más utilizado en las obras genealógicas para la creación de su identidad. Por otra parte, tampoco hay que olvidar la vinculación de los Bragança con el Campo de Toro desde los tiempos de Fernando Fernandes, donde este estilo arquitectónico es abundante.

\section{Los Bragança, Castro de Avelâes y Moreruela. Monasterios e identidad NOBILIARIA EN LAS OBRAS GENEALÓGICAS PORTUGUESAS}

Las fuentes genealógicas, creadas en el ámbito nobiliario, fueron utilizadas para construir la identidad, imagen y memoria de los nobles. El caso de los Bragança es especialmente llamativo, puesto que en todos los libros de linajes portugueses, que se redactaron desde finales del siglo XIII hasta mediados del siglo XIV, la familia se vincula al monasterio de Castro de Avelães; lo que indica el especial interés que tenía por ligarse a este centro desde su origen.

En el prólogo del Livro Velho el autor presenta a las cinco principales familias de la nobleza portuguesa, situando a los Bragança en segundo lugar de importancia ${ }^{76}$. Es la única a la que el autor vincula, desde su origen, a un centro monástico, construyendo una pequeña narrativa en la que se combinan tres elementos que las parentelas utilizaron para construir su identidad, su memoria y la imagen de su poder: el recurso al origen en un príncipe, en este caso princesa extranjera ${ }^{77}$, su vinculación con la monarquía, y el arraigo al espacio con anterioridad al nacimiento de la monarquía lusitana. Así, en el prólogo del Livro Velho el autor señala que:

Don Alam, que foi clerigo filho d'algo e filhou a filha d'el rei de Armenia quando foi em oração a Santiago, e foi sa hospeda em San Salvador de Crastro de Avelãas, e filhou-a com seu linhagem e enviou as companhas suas para sa terra, e ficou ele com ela, e fege nela dous filhos donde vieram os linhagens dos Bragançãos ${ }^{78}$.

En esta narrativa no es la tierra la que sirve de referencia a la parentela para construir la identidad, sino el propio edificio del monasterio. Aporta una destacada información, como la existencia de un centro monástico en Castro de Avelães, aunque la construcción que se conserva en la actualidad está datada en la segunda mitad del siglo XII. Parece una elaboración ficticia del autor del Livro Velho, efectuada a finales del siglo xiII, para mostrar el arraigo de los Bragança en este espacio, en un tiempo de gran presión por parte de Don Dinis de Portugal frente al poder nobiliario. En ese hipotético primer edificio en Castro de Avelāes ${ }^{79}$, profesaría don Alão que hospedó a la princesa armenia que se

76 Véase esquema genealógico III.

77 Ferreira, M. a do Rosário. «El poder de las mujeres en los Livros de linhagens». E-spania, 2020, vol. 36, https://journals.openedition.org/e-spania/35577

$78 \mathrm{LV}$, prólogo.

79 No existe constancia documental ni arqueológica de la existencia de este primer edificio. 
PETRIFICANDO LA RIQUEZA FAMILIAR MÁS ALLÁ DE LA FRONTERA. LA CONSTRUCCIÓN COMO

dirigía a Santiago de Compostela en peregrinación, y de cuya relación descenderían los Bragança. El Livro do Deão y el Livro de Linhagens del Conde don Pedro, redactados en la segunda mitad del siglo XIV, obvian la referencia al monasterio en la narrativa del origen de la parentela.

No es la única narrativa que vincula a los Bragança con el edificio, sino que el conde don Pedro en su Livro de Linhagens añade un relato en el que Castro de Aveláes es el referente para construir la identidad de la familia y para destacar, una vez más, la estrecha relación que mantienen con la familia real. La protagonista de esta narrativa es María Pais da Ribeira, hija de Elvira Nunes de Bragança y Paio Moniz da Ribeira. La famosa Ribeirinha había sido concubina de Sancho I de Portugal desde 1200 hasta la muerte del monarca en 1211.

E este Lourenço nom foi casado, mas filhou por força em Avelãas, dona María Paaes Ribeira, que se vinha de Coimbra, u soterrara u rei dom Sancho de Portugal, que a trazia consigo, e de que havia seus filos, dom Rodrigo Sanchez e dom Gil Sanchez e dona Teresa Sanchez e Constança Sanchez. E ela viindo assi mui triste com seu doo pera sa terra e pera mui grande algo que ela havia, e como muito honrada que era, viindo com ela seu irmão dom Martim Paeez Ribeiro, sahio a ela ao camino o sobre dito Gomez Lourenço e filhou-a por força, e foi chegado son Martim Paaz Ribeiro, seu irmáo. E levou-a pera terra de Leom, ca non ousava ficar na terra, cae la era mui aparentada, e pelos filhos que avia ${ }^{80}$.

En esta narrativa, el conde don Pedro dibuja a dońa María como una mujer afligida por la pérdida del monarca a quien acababa de dar sepultura en Coimbra. Es la imagen de una viuda, aunque no hubiera contraído matrimonio legítimo con el rey, que, junto a sus cuatro hijos, se dirigía a pasar el luto a Castro de Avelães. De nuevo, el monasterio se muestra como un espacio de refugio para los miembros de la familia. En este caso, el cenobio daría cobijo a la mujer y los hijos el rey muerto, ahondando así en la idea de la vinculación de los Bragança con la monarquía lusitana. En esta ocasión, el conde don Pedro también hace referencia a la tierra en la que se encuentra el monasterio, en la que los parientes de la mujer eran muy poderosos. Pero antes de llegar al Castro de Avelães, donde estaría a salvo, fue raptada por Lorenço de Alvarenga, que la llevó a León. El autor también la presenta como una mujer bien emparentada en León, donde tendría la ayuda del monarca que junto a su primo, Fernando Fernandes de Bragança, le ayudarían a liberarse del Alvarenga ${ }^{81}$.

Pero la naturaleza transfronteriza de los Bragança y su servicio a los monarcas leoneses, les vinculó también al monasterio Santa María de Moreruela. Su relación se estrechó tras el matrimonio de Mendo de Bragança y Sancha Ponce (de Cabrera) ${ }^{82}$.

El conde don Pedro incluye una narrativa que permite conocer la vinculación simbólica de los Bragança con Moreruela. El monasterio se convierte en el escenario de ciertos rituales en los que se ve implicado el grupo de parientes. Se trata de un juramento

80 LL 36BN10.

81 Calderón Medina y Ferreira Martins, «Os senhores», pp. 140-142.

82 Véase esquemas genealógicos II y III. 
entre dos hermanos: Rui Mendes y Fernando Mendes «O Bravo», hermanos de Mendo de Bragança, esposo de Sancha Ponce. El Livro de Linhagnes relata que:

Don Fermam Meendez o Bravo, e Ruiz Meendes, que cegou entrante à lide que houve com o seu irmão don Fernam Meendez, porque lhi jurara em Santa Maria de Moreirola que non fosse contra ele, e porque passou o juramento que fezera em Santa Maria de Moreirola, cegou entrante à lide, e morreo nela ${ }^{83}$.

El conde don Pedro reitera que el juramento se hizo en el monasterio de Moreruela. Soares Machado lo data con posterioridad a $1174^{84}$. En él, Rui Mendes juró a su hermano, Fernando Mendes de Bragança, que no iría contra él. Tras romper el juramento, ambos hermanos se enfrentaron en una lid y Fernando cegó a Rui, que moriría poco después.

Son pocas las noticias conservadas acerca de los juramentos que se hacían en monasterios en los reinos ibéricos occidentales, aunque las fuentes han descrito algunos de ellos. En 1129 se celebraron varios juramentos en el monasterio de Sahagún, en San Zoilo de Carrión y Santa Eulalia, con motivo del viaje de Berenguela de Barcelona a León para contraer matrimonio con Alfonso VII ${ }^{85}$. Asimismo, en 1156 Nuño Meléndez, obligado por su madre, ante los hombres principales de su parentela, juró en el altar de San Salvador de Oviedo, que no desheredaría a sus hermanas ${ }^{86}$. En todos los casos, el juramento se hizo sobre el altar y ante testigos, entre los que se encontraban los principales hombres de la parentela y, en ocasiones, de la corte regia. Así, es posible suponer que, en el altar de la Iglesia de Santa María de Moreruela, Rui juró que no atacaría a su hermano, teniendo como testigos a sus parientes.

Esta narrativa permite observar que el monasterio fue el escenario sagrado en el que los hermanos decidieron solucionar el conflicto, que les enfrentaba y que estaba dividiendo a la parentela. Tras la ruptura del juramento por parte de Rui, ambos hermanos se enfrentaron en una lid; Fernando cegó a Rui que murió poco después, aunque se desconoce en qué circunstancias y si fue enterrado en Moreruela. De este modo, el hermano triunfante se puso al frente de la parentela. Su bisnieto Fernando Fernandes de Bragança tendría a lo largo de su vida una estrecha relación con el monasterio. Esta narrativa, cuyo

83 LL 38A3.

84 Soares Machado, Os Bragançãos, p. 92.

85 Martínez Sopena, Pascual. «El camino de Santiago. Teatro de guerra y alianza». En Herrero de la Fuente, Marta et al. (eds.). Alma Littera. Estudios dedicados al profesor José María Ruiz Asencio. Valladolid: Universidad de Valladolid, 2014, pp. 441-449.

86 Fernández Flórez, José Antonio y Herrero de la Fuente, Marta. Colección diplomática del monasterio de Santa María de Otero de las Dueñas. Vol. II (1109-1300). León: Centro de Estudios San Isidoro, 2006, doc. 352 describe cómo se hacían este tipo de juramentos ente un conflicto entre hermanos frente al altar y teniendo por testigos a los principales parientes: Ego Maria Frolez, filia comitis Floilani et comitisse domne Stephanie, timeo et reuereor maleditionem quam posuit mater mea super fliabus meis; et ego, desiderando beneditiolnem quam dedit filio meo, accepi consilium cum uiris obtimis, scilicet, domno Petro Alfonsi, meo uiro, et meo fratre comite dompno Ramiro et cum puxore eius comitissa domna Elo et cum meo cognato Uelasco Sancii et cum aliis multis obtimis uiriis, et feci iurari filium meum dompnum Nunnum ante illos et ante altare Sancti Saluatoris Ouetensis, in fide et rei ueritate, quod nunquam deshereditasset illas pro re quam facerent. 
PETRIFICANDO LA RIQUEZA FAMILIAR MÁS ALLÁ DE LA FRONTERA. LA CONSTRUCCIÓN COMO

índice de verosimilitud es alto, permite observar el papel simbólico que el monasterio tuvo en la parentela y cómo los Bragança lo utilizaron para legitimar un cambio de liderato en la parentela, además de justificar el poder y la vinculación que el bisnieto del protagonista, Fernando Fernandes de Bragança tuvo con Moreruela.

Estos tres relatos muestran cómo los Bragança se vincularon, desde su origen, a los monasterios que patrocinaron o con los que tuvieron una estrecha relación, como un elemento para construir su identidad, legitimar su poder, y perpetuar esta relación en la memoria.

3 Casas, castillos e identidad nobiliaria. El testimonio de las InQuiriçóes GERAIS DE 1258

A pesar de que la mayor parte de la documentación diplomática de este espacio transfronterizo informa sobre la construcción de edificios eclesiásticos, las Inquiriçóes permiten localizar referencias a la edificación de estructuras residenciales y productivas, que representaban un destacado papel de cohesión familiar, pues, durante generaciones, eran frecuentadas por el grupo de parientes.

Las Inquiriçôes aluden a la construcción de quintãas en las que siempre figuraba una casa, que, además de residencia de la familia en el tiempo en que permanecían en ella, era el lugar de referencia en el que los campesinos entregaban sus prestaciones. Alves Gameiro ha señalado que, mientras que en los territorios en los que los nobles tenían poca implantación territorial hacían uso de su derecho de "aposentadoría», alojándose en las casas de sus vasallos; en los solares en los que tenían un mayor arraigo patrimonial construían quintãas, que les permitía una mejor administración de sus dominios. Así se registran varias casas de los Sousa en Tràs-òs-Montes ${ }^{87}$, o las que Ponce Alfonso Baião, hijo de Teresa Peres de Bragança ${ }^{88}$, poseyó en Santa Cruz de Valariça ${ }^{89}$. En este caso, además de las casas, Pedro Alfonso mandó construir otras infraestructuras para las labores de producción agrícola: et fecit ibi unum molinum, que se convirtió en un edificio referencial para los campesinos de su señorío. Una generación más tarde, sus vasallos señalaban quién y en qué circunstancias, había construido el molino y cómo había sido heredado por sus hijos, que eran los propietarios en $1258^{90}$.

A partir de la segunda mitad del siglo XII se registran en Portugal los primeros casos de construcción de casas torre. Son el nuevo símbolo del poder señorial ${ }^{91}$. Fueron edificadas en piedra por parte de una nobleza media que necesitaba reafirmarse frente a los

87 Alvez Gameiro, A construção das memorias nobiliárquicas, pp. 61-62.

88 Era hijo de Teresa Peres de Bragança y Alfonso Hermiges de Baião.

89 Situada en Torre de Moncorvo, próximo a Bragança.

90 PMH, INQ 1258, 1275a: Gonçaluus Menendi de Turre de Menendo Coruo iurado et interrogatus dixit quod scit quod homines de Sancta Cruce dederunt Domno Poncio Alfonsi hereditates et domos in ipsa uila de Sancta Cruce, quando populauerunt eam, et ipse Domnus Poncius Alfonsi fecit ibi unum molinum et modo filii ipsius Domini Ponci Alfonso tenent ipsam molinum et ipsas domus et hereditates et non faciunt forum Domno Rege.

${ }_{11}$ Mattoso, José. Ricos homens, infançöes e cavaleiros. A nobreza medieval portuguesa nos séculos XI a XIII. Lisboa: Guimarães, 1982, p. 150. 
PETRIFICANDO LA RIQUEZA FAMILIAR MÁS ALLÁ DE LA FRONTERA. LA CONSTRUCCIÓN COMO ELEMENTO DE CREACIÓN DE IDENTIDAD Y MEMORIA NOBILIARIA ENTRE LEÓN Y PORTUGAL INÉS CALDERÓN MEDINA

antiguos linajes. Así, los Cunha en 1171 edificaron su domus fortis ${ }^{92}$. Pero será a partir del siglo XIII, cuando el fenómeno se consolide y aparezcan otros ejemplos, como la torre de los Vasconcelos ${ }^{93}$, o la torre de Refóios de Lima, situada al sur del Miño en la tierra de Limia, también fronteriza ${ }^{94}$.

En el espacio delimitado en este trabajo no se han localizado claros testimonios documentales de la construcción de domus fortis, pero en la tierra de Miranda, se registra la construcción de estructuras defensivas, por parte de un cierto noble. Se trata del castillo de Ulgoso, cuya construcción atribuyen los testigos de las Inquiriçóes a Mendo Bonfim, padre de Alfonso Mendes de Bornes, miembros de una nobleza media ascendente, asentada en Miranda. Don Mendo era hermano de Rodrigo Bonfim a quien en 1186 Sancho I le cambió una heredad en Vimioso, en término de Miranda, por otra en Cernadella ${ }^{95}$.

Las referencias al castillo de Ulgoso datan de 1258, ya con la denominación de castillo; sin embargo, es probable que Mendo Bonfim comenzara a construirlo, en piedra, en la década de los 70 u 80 del siglo XII. El capellán de la iglesia de San Vicente de Vimioso, declaró en 1258 que, en ese momento, la iglesia era propiedad de Pedro Ponce de Cabrera, hijo de Ponce Vela, bisnieto de Ponce de Cabrera ${ }^{96}$, pero que había oído decir que esa aldea se la entregó Sancho I a Mendo Bonfin pro castello de Ulgoso, quem fecit ipse Menendus Busino ${ }^{97}$. Esta referencia y la carta del rey a su hermano Rodrigo Bofim, hace pensar que el cambio de Ulgoso por Vimioso aconteció en torno a 1186, cuando el monarca estaba intentando implementar su presencia en este espacio fronterizo ${ }^{98}$. No podemos conocer si don Mendo comenzó a construir una torre en la que residiría o si se trataba ya de un castillo con un claro carácter defensivo, situado en la frontera leonesa. Aunque debemos dejarlo en el ámbito de la hipótesis, las escasas referencias a esta construcción y el modo en el que el monarca se hizo con ella, tal vez puedan enmarcarse en el proceso que inició Sancho I para evitar la proliferación de casas fuertes ${ }^{99}$.

92 Barroca, Mário Jorge. «Em torno a residência senhorial fortificada. Quatro torres senhoriais na região de Amares». Revista de História, 1989, vol. 9, pp. 9-61. Barroca, Mário Jorge. «Torres, casas-torres ou casas-fortes. A concepção do espaço de habitação da pequeña e média nobreza na Baixa Idade Média portuguesa (sécs. XII- Xv)». Revista de História das Idéias, 1997, vol. 19, pp. 39-103.

93 Barroca, «Torres», pp. 79-81. Su construcción se inició en 1265.

94 Vieira da Silva, José Custódio. Paços medievais portugueses. Lisboa: Instituto Portugués do Património Arquitectónico, 2002, pp. 50-51.

95 ANTT/ Gavetas XI, mç6, doc. 18. La sospecha del parentesco entre ambos queda confirmada en las inquiriçôes de 1258, cuando narran que Alfonso Mendes de Bornes, compró la villa de Cernadella a su primo Gil Rodriguez, que la tenía de su padre a quien se la había cambiado el rey por Vimioso; PMH. INQ $1258,1270 \mathrm{~b}$

96 Pedro Ponce era hijo de Ponce Vela, uno de los hijos de Vela Gutiérrez y Sancha Ponce, la hija de Ponce de Cabrera.

${ }_{97} \mathrm{PMH}, \mathrm{INQ}$ 1258. $1284 \mathrm{~b}$.

98 Sancho I otorgó fuero a Bragança en 1187.

99 Barroca, «Torres», pp. 98-99. Barroca, «Em torno a residência», pp. 83-99. Este fenómeno ha sido analizado por Barroca que señala los primeros casos, acontecidos a partir de 1171, en los que el monarca manda destruir la casa torre de los Cunha. Irá in crescendo a medida que se extiende la construcción de casas fuertes, sobre todo en el reinado de Sancho II. Serán Alfonso III y, sobre todo, D. Dinis quienes tomen serias disposiciones para impedirlo. 
PETRIFICANDO LA RIQUEZA FAMILIAR MÁS ALLÁ DE LA FRONTERA. LA CONSTRUCCIÓN COMO ELEMENTO DE CREACIÓN DE IDENTIDAD Y MEMORIA NOBILIARIA ENTRE LEÓN Y PORTUGAL INÉS CALDERÓN MEDINA

Pero también puede estar en consonancia con su proyecto de fortalecimiento del poder real en la frontera de León, con quien las relaciones se tensaban por momentos.

El castillo estuvo en posesión del monarca, aunque el rey de León se hizo con él tras la invasión de este territorio entre 1212 y 1213 , cuando se lo entregó a Fernando Fernandes de Bargança. Posteriormente, en 1223, Sancho II lo donó a la Orden del Hospital. Algunos testigos de las Inquiriçôes relatan que fue el monarca, Sancho II, quien entregó el castillo a los hospitalarios; mientras que otros describen una secuencia distinta de los hechos, en la que afirman que el rey de León se lo entregó a Fernando Fernandes de Bragança, y éste lo donó a los hospitalarios ${ }^{100}$. Parece que los testigos de las Inquiriçóes no recuerdan con nitidez la secuencia de quienes tuvieron el castillo, pero sí quien lo construyó y cómo se lo cambió a Sancho I por la villa de Vimioso. Desafortunadamente, poco se conoce de la primera construcción efectuada por Mendo Bonfim en el siglo XII, pues los hospitalarios llevaron a cabo una importante reestructuración.

El hijo de Mendo Bonfim, Alfonso Mendes de Bornes tuvo una gran vinculación con Moreruela. Entre los bienes que heredaron sus hijos en tierra de Miranda destacan varias iglesias, de las que eran patronos. Algunas de ellas se deterioraron o fueron abandonadas. Así lo declaran a los inquiridores los testigos de la parroquia de San Miguel de Cernelleda, que afirman que los hijos de Alfonso Mendes de Bornes, tenían el patronazgo de la iglesia y que, además tenían la mitad de la iglesia de San Pedro de Freóes, cuya otra mitad era del monasterio de Moreruela. No sabían cómo había llegado a sus manos, pero habían oído decir que había sido del rey. Además, recuerdan que la iglesia solía tener siete clérigos y que en ella se habían criado los hijos de Fernando Cogominho y Juan Arias. Sin embargo, en ese momento de 1258, la iglesia est destructa quod non habentur ibi clerici nec dicunt ibi misam et nec pulsam signum, pro illa criancia de illis filiis de Fernando Cogomino e Johanne Ayrie $e^{101}$.

No parece que hubiera habido un conflicto que conllevara la destrucción intencionada del templo. Posiblemente ese estado de abandono y pérdida de la función espiritual y principal de la iglesia, y la salida de los monjes, esté relacionado con la disminución de los ingresos de la parroquia, debido al derecho de amádigo, que le había hecho exenta de pagar tributos al rey, anterior propietario de la iglesia ${ }^{102}$. El hecho de que la parroquia fuera "honrada» y que ni la propia iglesia, ni los hijos de Alfonso Mendes, ni el monasterio de Moreruela recibieran rentas, provocó el desuso, abandono y la posterior ruina del edificio, cuyo material constructivo se desconoce. Llama la atención que a pesar de que en 1258 era un edificio en ruina, los testigos aún lo vinculaban con sus propietarios.

100 PMH, INQ 1258. 1278b, 1280a.

$101 \mathrm{PMH}, \mathrm{INQ}$. 1258. 1271b.

102 El derecho de amádigo está vinculado a la crianza de los hijos de los reyes o los nobles por parte de personas no nobles o clérigos. Esta función hace «honrada» o exenta a la tierra en la que se llevó a cabo la crianza, de pagar los tributos al rey de manera perpetua. El hijo o hija del noble criado se convertirá, parcialmente en heredero de quien lo crió, junto a sus hijos y la tierra mantendría a perpetuidad la exención fiscal. 
PETRIFICANDO LA RIQUEZA FAMILIAR MÁS ALLÁ DE LA FRONTERA. LA CONSTRUCCIÓN COMO ELEMENTO DE CREACIÓN DE IDENTIDAD Y MEMORIA NOBILIARIA ENTRE LEÓN Y PORTUGAL INÉS CALDERÓN MEDINA

\section{Conclusiones}

El gasto de la nobleza en la petrificación de edificios fue destacado desde el siglo XI, aunque las fuentes indican que aumentó a partir de la segunda mitad del siglo XII. La nobleza transfronteriza destinó una parte importante de su patrimonio en construir edificios, laicos y eclesiásticos, a ambos lados de la frontera para crear su identidad en ambos reinos, vinculando su imagen y memoria con ellos.

Los Muñoz edificaron el monasterio particular San Salvador de Villacete. En el momento de entregárselo a Sahagún se ilustró el documento en el que relataban los motivos de su construcción, con una miniatura que vinculaba la imagen de los fundadores al edificio que habían construido, al tiempo que perpetuaba su memoria en el monasterio al que lo habían entregado.

Ponce de Cabrera fue recordado como constructori Morerole. Él y sus descendientes financiaron y planificaron, junto al maestro de obras, la construcción en piedra de Moreruela y San Esteban de Nogales. Ambos se convirtieron en los lugares de creación de identidad y memoria de su familia, pues en ellos recibieron sepultura algunos de sus miembros. Al otro lado de la frontera, los Bragança promovieron la edificación de Castro de Avelães, que afiliaron a San Martín de Castañeda. Construido en ladrillo, se convierte en un ejemplo excepcional en el territorio hoy portugués. Tal vez, con la construcción en ladrillo los Bragança estaban intentando vincularse con Alfonso VI, su antepasado más insigne.

Su relación con la monarquía y con Castro de Avelães fue utilizada por los Bragança para construir su identidad en los libros de linajes, en los que claramente el cenobio es su referente. También utilizaron las genealogías para justificar su relación con Moreruela y explicar un cambio de liderato en la familia dentro de su recinto sagrado.

Pero además de los monasterios, los nobles también construyeron otros edificios como sus propias casas, molinos, iglesias o castillos que se identificaban con su poder. Así eran recordados generaciones después por los testigos de las Inquiriçóes Gerais de 1258, lo que permite comprobar cómo se identifica al promotor con su edificación a lo largo de los siglos.

La documentación diplomática, las genealogías y declaraciones de los testigos de las Inquiriçóes han permitido observar el enorme esfuerzo económico de la nobleza para construir su identidad, pero también el triunfo de ese proyecto, pues durante generaciones fueron recordados como los constructores de las edificaciones que habían promovido. 
PETRIFICANDO LA RIQUEZA FAMILIAR MÁS ALLÁ DE LA FRONTERA. LA CONSTRUCCIÓN COMO ELEMENTO DE CREACIÓN DE IDENTIDAD Y MEMORIA NOBILIARIA ENTRE LEÓN Y PORTUGAL INÉS CALDERÓN MEDINA

\}

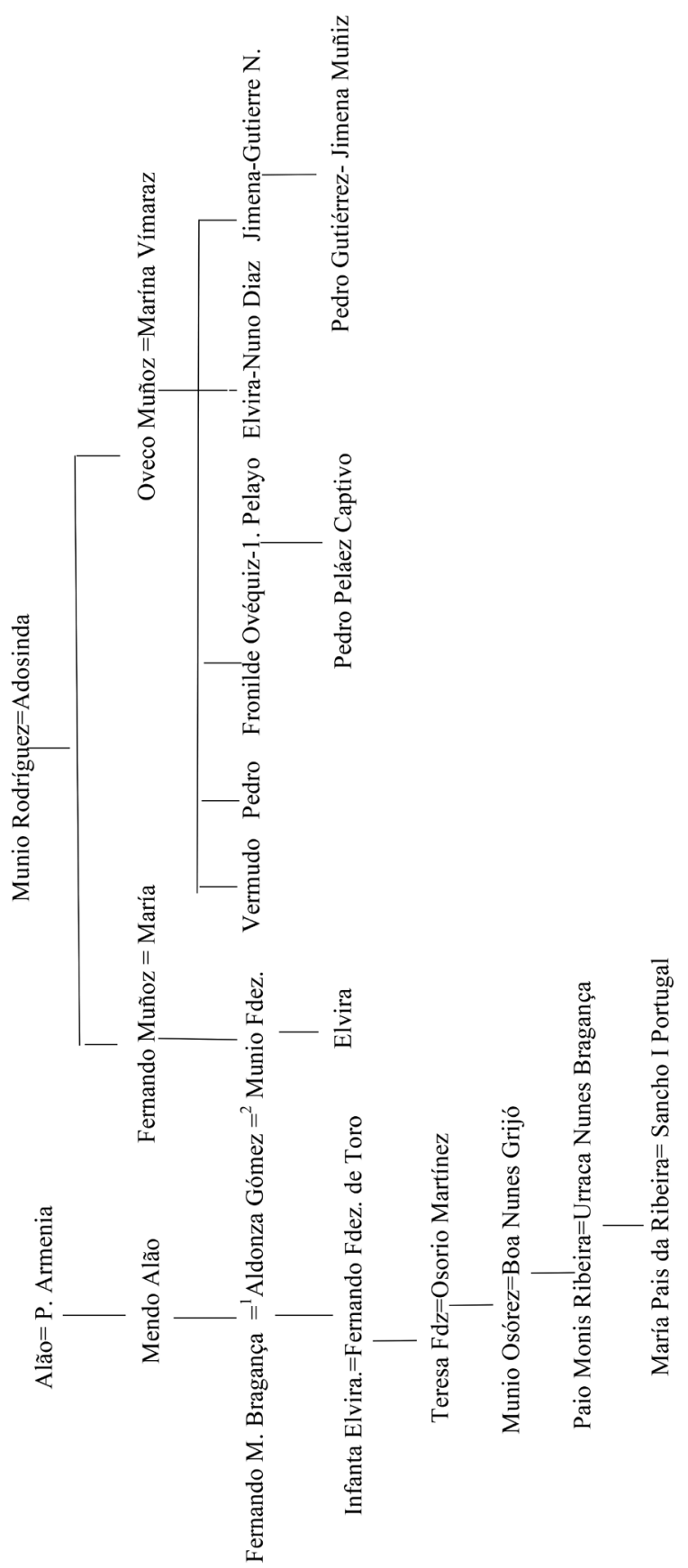


90 PETRIFICANDO LA RIQUEZA FAMILIAR MÁS ALLÁ DE LA FRONTERA. LA CONSTRUCCIÓN COMO ELEMENTO DE CREACIÓN DE IDENTIDAD Y MEMORIA NOBILIARIA ENTRE LEÓN Y PORTUGAL INÉS CALDERÓN MEDINA

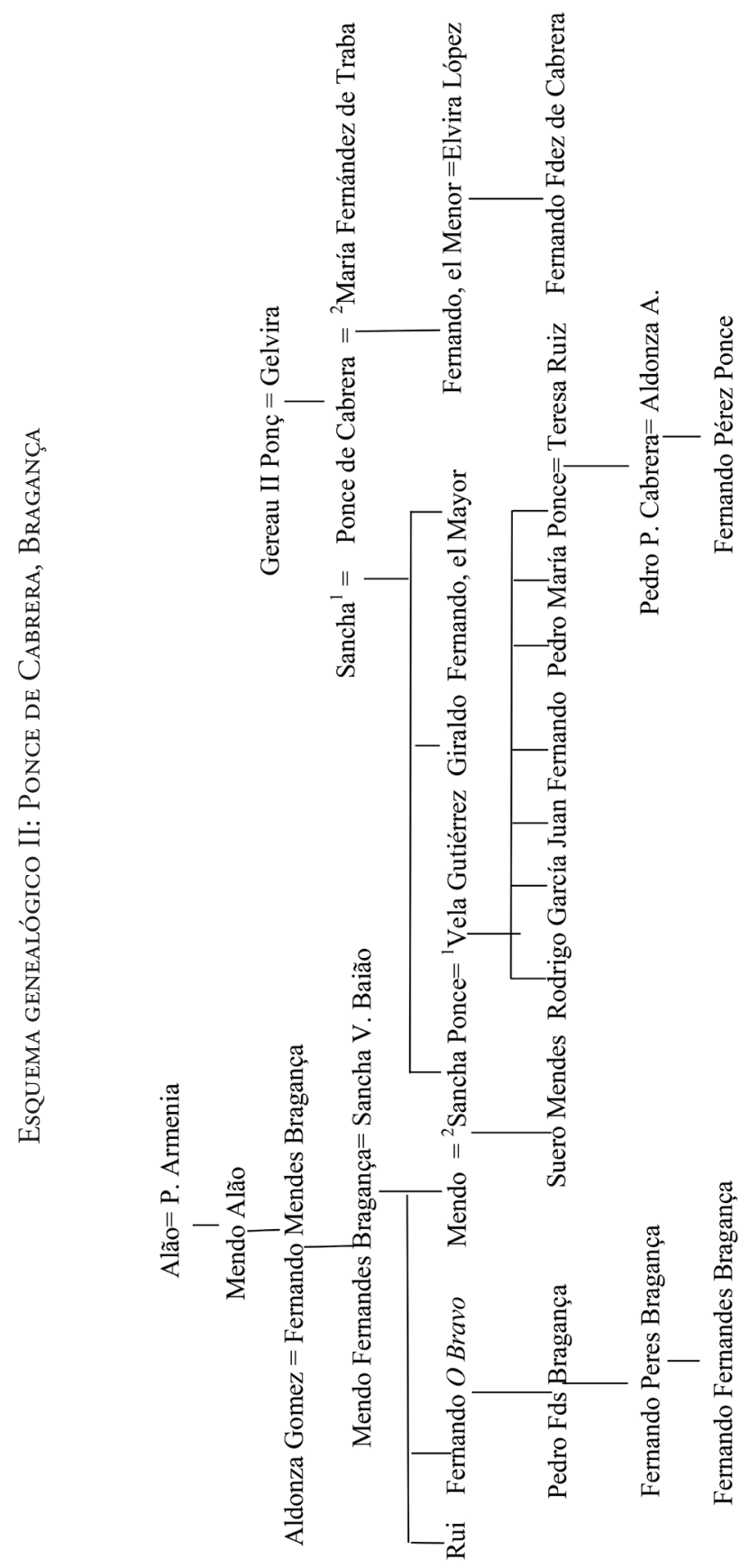


PETRIFICANDO LA RIQUEZA FAMILIAR MÁS ALLÁ DE LA FRONTERA. LA CONSTRUCCIÓN COMO ELEMENTO DE CREACIÓN DE IDENTIDAD Y MEMORIA NOBILIARIA ENTRE LEÓN Y PORTUGAL INÉS CALDERÓN MEDINA

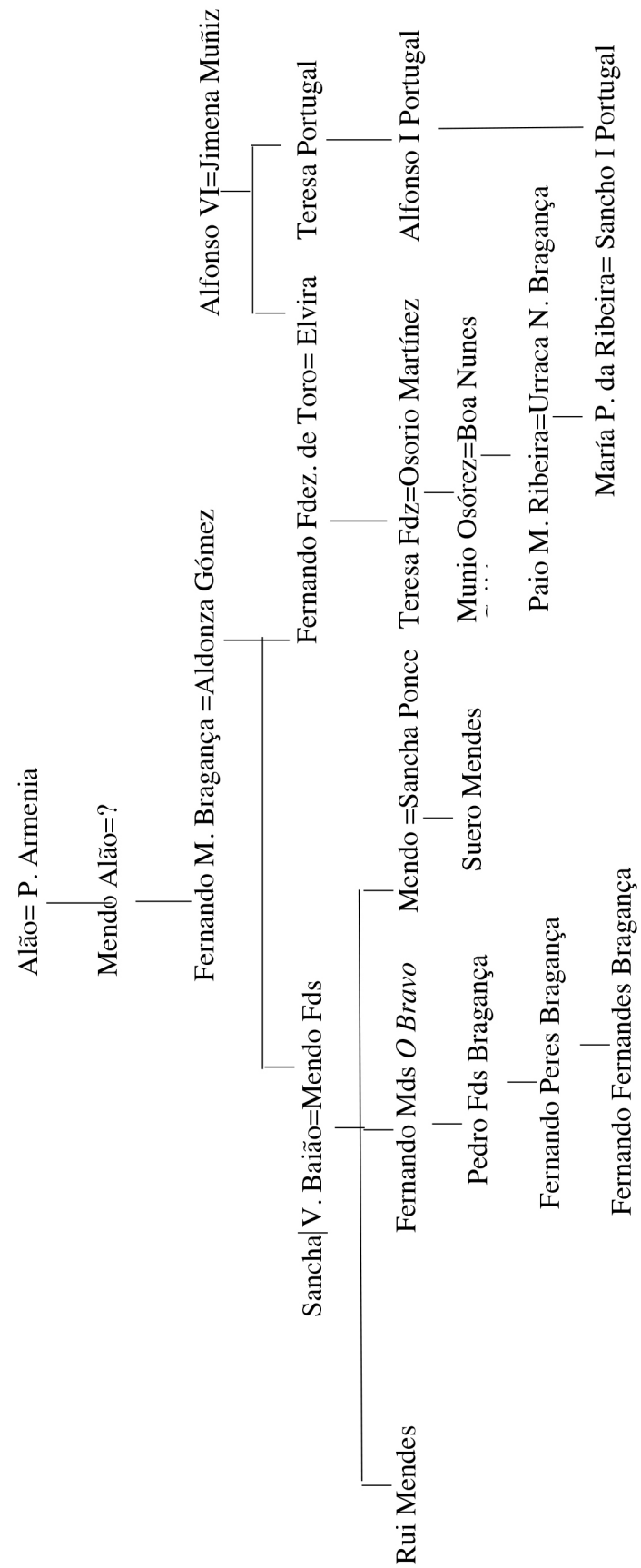


92 PETRIFICANDO LA RIQUEZA FAMILIAR MÁS ALLÁ DE LA FRONTERA. LA CONSTRUCCIÓN COMO ELEMENTO DE CREACIÓN DE IDENTIDAD Y MEMORIA NOBILIARIA ENTRE LEÓN Y PORTUGAL INÉS CALDERÓN MEDINA

\section{REFERENCIAS BIBLIOGRÁFICAS}

Alfonso Antón, Isabel. La colonización cisterciense de la Meseta del Duero. El dominio de Moreruela (siglos XII-XIV). Zamora: Instituto de Estudios Zamoranos Florián Ocampo, 1986.

Almeida Fernandes, Paulo. "Castro de Avelās: o estranho caso de uma igreja de tijolo». Monumentos: revista semestral de edificios e monumentos, 2011, vol. 32, pp. 84-95.

Alonso Álvarez, Raquel. «Los promotores de la Orden del Císter en los reinos Castilla y León». Anuario de Estudios Medievales, 2007, vol. 37, n. ${ }^{\circ}$ 2, pp. 653-710.

Barroca, Mário Jorge. «Em torno a residência senhorial fortificada. Quatro torres senhoriais na regiáo de Amares». Revista de História, 1989, vol. 9, pp. 9-61.

Barroca, Mário Jorge. «Torres, casas-torres ou casas-fortes. A concepção do espaço de habitação da pequeña e média nobreza na Baixa Idade Média portuguesa (sécs. XII- Xv)». Revista de História das Idéias, 1997, vol. 19, pp. 39-103.

Barton, Simon. The aristocracy in twelfh-century Leon and Castile. Cambridge: Cambridge University Press, 1997.

Beceiro Pita, Isabel. «Los poderes señoriales en los territorios fronterizos al Norte del Duero, ss. XIII-inicios del XIV)». Revista de Faculdade de Letras, 1998, vol. 15, n. o 2, pp. 1085-1100.

Calderón Medina, Inés. «El impulso nobiliario a la expansión del Císter en el Reino de León. La parentela de Ponce de Cabrera en los monasterios de Santa María de Moreruela y San Esteban de Nogales». Medievalismo, 2008, vol. 18, pp. 341-374.

Calderón Medina, Inés. Cum magnatibus regni mei. La nobleza y la monarquía leonesas durante los reinados de Fernando II y Alfonso IX de León (1157-1239). Madrid: CSIC, 2011.

Calderón Medina, Inés. Los Soverosa una parentela nobiliaria entre tres reinos. Poder y parentesco en la Edad Media Hispana, (ss. XI-XIII). Valladolid: Universidad de Valladolid, 2018.

Calderón Medina, Inés. «La movilidad nobiliaria en las fuentes medievales hispánicas. Hagiografías, cantigas y genealogías». En Reglero de la Fuente, Carlos (ed.). Poderes, espacios y escrituras. Los reinos de Castilla y León (siglos XII-XIV). Madrid: Sílex, 2018, pp. 15-53.

Calderón Medina, Inés y Ferreira Martins, João Paulo. "Os senhores de Cabreira e Ribeira. Um estudo sobre a sua origen e transcendencia peninsular, (séculos XII-XIV)». Revista Portuguesa de História, 2013, vol. 44, pp. 123-152.

Calderón Medina, Inés y Ferreira Martins, João Paulo. «Beyond the border. The aristocratic mobility between the kingdoms of Portugal and León (1157-1230)». E-journal of Portughese History, 2014, vol. 12, n. ${ }^{\circ}$ 1, pp. 1-48.

Cavero Domínguez, Gregoria. Colección documental del monasterio de San Esteban de Nogales (1149-1498). León: Centro de Estudios San Isidoro, 2001.

Cavero Domínguez, Gregoria. El esplendor del Císter en León. León: Fundación Hullera vascoleonesa, 2007.

De Yepes, Antonio. Crónica General de la Orden de San Benito. Valladolid: Fernández de Córdova, 1617.

Fernández Flórez, José Antonio y Herrero de la Fuente, Marta. Colección diplomática del monasterio de Santa María de Otero de las Dueñas. Vol. II (1109-1300). León: Centro de Estudios San Isidoro, 2006.

Fernández Xesta, Ernesto. Un magnate catalán en la corte de Alfonso VII. Comes Poncius de Cabreira, princeps Çemore. Madrid: Prensa y Ediciones iberoamericanas, 1991.

Ferreira de Almeida, Carlos Alberto. História da Arte em Portugal. O románico. Lisboa: Presença, 2001. 
PETRIFICANDO LA RIQUEZA FAMILIAR MÁS ALLÁ DE LA FRONTERA. LA CONSTRUCCIÓN COMO ELEMENTO DE CREACIÓN DE IDENTIDAD Y MEMORIA NOBILIARIA ENTRE LEÓN Y PORTUGAL INÉS CALDERÓN MEDINA

Ferreira do Amaral, José Augusto. «A linhagem dos Bragançãos- Parte I». Armas e Troféus, 2016, vol. 9, pp. 259-319.

Ferreira do Amaral, José Augusto. «A linhagem dos Bragançãos- Parte II». Armas e Troféus, 2017, vol. 10, pp. 247- 274 .

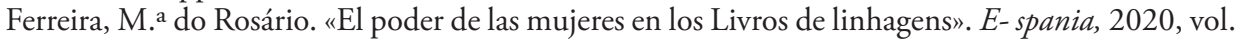
36, https://journals.openedition.org/e-spania/35577

García, Charles. «El magnate, la mujer y el abad. Iconografía y memoria de los antepasados en el territorio de la actual Zamora». Studia Zamorensia. Segunda Etapa, 1999, vol. 5, pp. 9-22.

García, Charles. Le Campo de Toro au Moyen Âge. Peuplement, seigneuries et société (IXe-XIV siècles). Paris: Atélier National de Reproduction de théses, 2002.

García, Charles. "La territorialisation du Campo de Toro au Moyen Âge (IX-XI ${ }^{\text {ème }}$ siècles)». Pandora: revue d'etudes hispaniques, 2010, vol. 10, pp. 17-32.

Herrero de la Fuente, Marta. Colección Documental del Monasterio de Sahagún. Tomo II (10001073). León: Centro de Estudios San Isidoro, 1998.

Martín Viso, Iñaki. «La feudalización de valle de Sanabria, siglos X-XIII». Studia Historica. Historia Medieval, 1993, vol. 11, p. 33-55.

Martín Viso, Iñaki. «La formación de la frontera con Portugal y su impacto en el occidente zamorano (siglos XII-XIII)». Studia Zamorensia, Segunda etapa, 2002, vol. VI, pp. 49-74.

Martínez Sopena, Pascual. «Monasterios particulares, nobleza y reforma eclesiástica en León entre los siglos XI y XII». En VV. AA., Estudios de Historia medieval. Homenaje a Luis Suárez Fernández. Valladolid: Universidad de Valladolid, 1991, pp. 323-331.

Martínez Sopena, Pascual. «Aristocracia, monacato y reformas en el siglo XI y XII». En El monacato en los reinos de León y Castilla (siglos VII-XIII). Ávila: Fundación Sánchez-Albornoz, 2005, pp. 67-100.

Martínez Sopena, Pascual. «El camino de Santiago. Teatro de guerra y alianza». En Herrero de la Fuente, Marta et al. (eds.). Alma Littera. Estudios dedicados al profesor José María Ruiz Asencio. Valladolid: Universidad de Valladolid, 2014, pp. 441-449.

Mattoso, José (ed.), Livro de Linhagens do Conde D. Pedro. En Portugaliae Monumenta Historica. Nova Série, vol. II, Lisboa: Academia das Ciências de Lisboa, 1980.

Mattoso, José. Ricos homens, infançôes e cavaleiros. A nobreza medieval portuguesa nos séculos XI a XIII. Lisboa: Guimarães, 1982.

Miguel Hernández, Fernando. «Aproximación arqueológica al monasterio de Santa María de Moreruela». Anuario del Instituto de Estudios Zamoranos Florián Ocampo, 1994, vol. 11, pp. 56-76.

Oliveira, Carlos. «O mosteiro beneditino de São Salvador de Castro de Avelãs no povoamento da região bragançana». Brigantia, 1991, vol. XI, n. ${ }^{\circ} 1-2$, pp. 33-46.

Pérez, Mariel. «El control de lo sagrado como instrumento de poderlos monasterios particulares de la aristocracia altomedieval leonesa». Anuario de Estudios Medievales, 2012, vol. 42, n. ${ }^{\circ}$ 2, pp. 799-822.

Piel, Joseph, y Mattoso, José. (eds), Livros Velhos de Linhagens. En Portugaliae Monumenta Historica. Nova Série, vol. I, Lisboa: Academia das Ciências de Lisboa, 1980.

Portugaliae Monumenta Historica, (ed.) Inquisitiones. Lisboa: Academia das Ciências de Lisboa, 1961.

Reglero de la Fuente, Carlos. Los señorios de los montes Torozos: de la repoblación al Becerro de las behetrías (siglos X-XIV). Valladolid: Universidad de Valladolid, 1993.

Rodríguez González, Ángel. El Tumbo del monasterio de San Martín de Castañeda. León: Centro de Estudios San Isidoro, 1973. 
94 PETRIFICANDO LA RIQUEZA FAMILIAR MÁS ALLÁ DE LA FRONTERA. LA CONSTRUCCIÓN COMO ELEMENTO DE CREACIÓN DE IDENTIDAD Y MEMORIA NOBILIARIA ENTRE LEÓN Y PORTUGAL INÉS CALDERÓN MEDINA

Soares Machado, José Carlos. Os Bragançãos: história genealógica de uma linhagem medieval (séculos XI-XIII). Lisboa: Associação portuguesa de Genealogía, 2004.

Sottomayor Pizarro, José Augusto. Os patronos do mosteiro de Grijó: evolução e estrutura da familia nobre, séculos XI a XIV. Porto: Ediçóes Carvalhos de Bastos, 1995.

Sottomayor Pizarro, José Augusto. As linhagens medievais portuguesas. Estratégias. Oporto: Centro de Estudos de Genealogia, Heráldica e História da Família, Universidade Moderna, 1999.

Sottomayor Pizarro, José Augusto. "A aristocracia no territorio de Bragança, (séculos XI-XV)», En da Fonseca, Luis Adão, et al. Bragança na Idade Média. Bragança: Munícipio de Bragança, 2019, pp. 177-209.

Valdés Fernández, Manuel. La Arquitectura mudéjar en León y Castilla. León: Universidad de León, 1984.

Valdés Fernández, Manuel. «Arquitectura mudéjar y los sistemas constructivos en León y Castilla en torno a 1200». En Lacarra Ducay, M. ${ }^{a}$ del Carmen (coord.), Arquitectura mudéjar en Aragón, León, Castilla, Extremadura y Andalucía, Zaragoza: Institución Fernando el Católico, 2006, pp. 65-110.

Vieira da Silva, José Custódio. Paços medievais portugueses. Lisboa: Instituto Portugués do Património Arquitectónico, 2002. 